ISSN: 2238-8052

\title{
A LUTA DOS RIBEIRINHOS DO RIO XINGU, NA AMAZÔNIA BRASILEIRA E 0 SUCESSO DO AUTOGOVERNO, NO TERRITÓRIO ZAPATISTA MEXICANO
}

\author{
THE STRUGGLE OF THE RIVERINE PEOPLE OF THE XINGU RIVER, IN THE BRAZILIAN AMAZON \\ AND THE SUCCESSFUL OF THE SELF-GOVERNMENT, IN THE MEXICAN ZAPATISTA TERRITORY
}

Beatriz Maria Soares PONTES ${ }^{1}$

Palavras-chave: Ribeirinhos Usina Belo Monte Autogoverno Caracoles

Keywords: Riverine People Belo Monte Plant Self-Government Caracoles

\section{R E S U M O}

Este trabalho analisa, em primeiro lugar, a luta travada pelos ribeirinhos do Rio Xingu contra os representantes da Usina Belo Monte que os tiraram de suas terras de origem, representadas por ilhas muito próximas das margens do Rio Xingu e os realocaram em áreas urbanas ou rurais, distantes da margem do rio. Os ribeirinhos tiveram os seus direitos humanos ignorados, não foram dignamente indenizados quer pelas suas terras, quer pelas suas moradias e sua situação só melhorou quando foi fundado o Conselho dos Ribeirinhos, o qual teve como objetivo de maior relevo, o aprofundamento do diálogo desta comunidade com os representantes da Usina, dando particular ênfase à questão do seu reordenamento territorial, visando principalmente, o retorno às margens do Rio Xingu. Em segundo lugar, o estudo aborda o bem-sucedido autogoverno estabelecido no território zapatista mexicano, sob a égide de princípios como a autonomia, independência, liberdade e democracia. No ordenamento territorial realizado pelos integrantes do movimento zapatista podemos distinguir a existência de cinco caracoles, a saber: Morelia, La Garrucha, Roberto Barrios, Oventic e La Realidad.

\begin{abstract}
A B S T RA C T
This study examines, at first, the struggle waged by the riverine people of the Xingu River against the Belo Monte Plant representatives that took them from their origin land, represented by islands very close to the banks of the Xingu River and, relocated them in urban or rural areas, distant from the river bank. The riverine people have had their human rights ignored. They have not been properly indemnified for their lands and for their housing either. And their situation only improved when it was founded the Council of Riverine People, which had as their biggest goal the deepening of the dialogue of this community with the representatives of the Plant, with particular emphasis to the question of the territorial reorganization, aiming, mainly, the return to the banks of the Xingu River. Secondly, the study discusses the successful Self-Government established in the Mexican zapatista territory, under the aegis of the principles like autonomy, independence, freedom and democracy. In the spatial planning carried out by members of the zapatista movement we can distinguish the existence of five caracoles, namely: Morelia, La Garrucha, Roberto Barrios, Oventic and La Realidad.
\end{abstract}




\section{INTRODUÇÃO}

No presente estudo, no qual trazemos à lume a luta dos ribeirinhos do Rio Xingu, na Amazônia brasileira e o sucesso do autogoverno, no território zapatista mexicano, não entraremos no mérito das discussões teóricas, as quais já foram apresentadas em um trabalho anterior, no qual discutimos os Movimentos de Resistência Socioterritoriais pretéritos e Contemporâneos: América do Norte, América do Sul e África (FERNANDES, 2001). Portanto, no contexto atual, só ponderaremos sobre aspectos cruciais relativos aos movimentos de resistência socioterritoriais.

Em sua totalidade os movimentos são compreendidos como agentes criadores e recriadores de espaços e territórios. 0 movimento socioterritorial é um sujeito coletivo ou grupo social que se mobiliza para desenvolver uma determinada ação em defesa dos seus interesses, sobretudo aqueles relativos ao território.

A diferença que justifica a construção do conceito de movimento socioterritorial, parte da necessidade da geografia de realizar uma análise que vá além da leitura da relação sujeito-sujeito para sujeito-território.

Para evitar equívocos na compreensão do conceito de movimentos socioterritoriais é preciso esclarecer que o espaço social, ou seja, a dimensão social está contida no espaço geográfico, criado originalmente pela natureza e transformado continuamente pelas relações sociais (SANTOS, 2008).

\section{OS RIBEIRINHOS DO RIO XINGU}

O Paratizão é uma das muitas ilhas e pedaços de terra firme no Rio Xingu, alagados em 2015, com o objetivo de ceder espaço para o reservatório principal da Usina Hidrelétrica de Belo Monte. Portanto, cerca de duzentas famílias ribeirinhas que viviam nas ilhas muito próximas às margens do Rio Xingu foram removidas de suas casas denotando, claramente, uma contravenção aos direitos humanos daquela população tradicional.

Ainda que as famílias tivessem uma história e um modo de vida ligados ao território onde viviam, tais aspectos não foram considerados quando retiradas dos seus locais de origem e sequer lhes foram propiciadas alternativas adequadas para prosseguirem a sua vida de acordo com os seus objetivos e tradições.

De acordo com o cadastro do qual constavam as famílias removidas arbitrariamente, a usina em construção, seguiu uma forma de atuar em relação a essas famílias, extremamente violenta. As pessoas foram expulsas para o centro urbano e a zona rural da região de Altamira, que era muito distante do Rio, dando margem a que os ribeirinhos passassem a lutar para a salvaguarda e garantia 
dos seus direitos e, principalmente, detendo o firme propósito de retornar para as margens do Rio Xingu.

Assim, tendo em vista a situação dos expulsos, foi criado em novembro de 2016, o Conselho Ribeirinho, composto pelos próprios ribeirinhos. 0 referido Conselho passou a ser a instância coletiva reconhecida como soberana para enfrentar o desafio do reordenamento territorial de forma participativa e digna.

Tal contexto evidenciou algo inteiramente novo constatado na Amazônia brasileira quanto à questão relativa à construção de hidrelétricas naquela região, isto é, o retorno e o reassentamento dos ribeirinhos nas suas áreas de origem, onde tinha sido construído o reservatório principal da usina.

0 lugar da comunidade ribeirinha é, sem dúvida, à beira do rio.

Em 2011, após muita resistência e mudanças estruturais no projeto inicial, a hidrelétrica de Belo Monte começou a ser instalada na região. Para compensar os grandes e inevitáveis impactos socioambientais da usina, em uma das regiões de maior diversidade social e ecológica do mundo, foi elaborado um Plano Básico Ambiental, que continha obrigações que a empresa concessionária deveria cumprir para mitigar os efeitos da instalação. Parte desse plano era destinado a compensar os impactos sofridos pelos povos indígenas. Os ribeirinhos, no entanto, não foram considerados um grupo social diferenciado e nenhuma ação ou tratamento específico lhes foram destinados.

Devemos ressaltar que cerca de 40 mil pessoas foram removidas, cedendo lugar para a instalação da usina, bem como os reservatórios da mesma. Desta forma, os ribeirinhos constituíram o último grupo social a ser deslocado, não tendo havido, precedentemente, nenhum estudo específico que contemplasse o seu modo de vida.

Assim sendo, no cômpito geral, eram cerca de 1.175 pessoas residentes na região onde, hoje, está situado o principal reservatório da usina de Belo Monte.

Por outro lado, os posseiros moradores das ilhas do Xingu também não foram indenizados pela terra, quando dela foram removidos. Só foram indenizados pelas construções identificadas nas terras onde viviam. Constatamos que, em virtude das suas moradias serem muito simples, construídas na base da madeira, do barro e da palha, os proventos indenizatórios por eles recebidos foram diminutos.

Algumas famílias foram reassentadas longe das margens do Rio Xingu e, acrescentamos que outras famílias não lograram permanecer nos locais onde foram reassentadas, migrando para o centro urbano, passando a viver em condições muito precárias.

No decurso da realização do reassentamento das famílias ribeirinhas, a concessionária não considerou o vínculo que as mesmas tinham com o território e sequer ponderaram sobre as redes de vizinhança que constituíam o suporte da organização social dos ribeirinhos. 
Assim sendo, a dispersão das famílias, quer na cidade de Altamira, quer na esfera rural, acarretou a desestruturação da sociedade ribeirinha, além de ter como consequência, paralisado as atividades econômicas que eram inerentes àquela comunidade social que vivia às margens do Xingu.

Os representantes da hidrelétrica de Belo Monte efetuaram o cadastramento dos que iriam ser reassentados em outros lugares, avisando que a partir daquele momento, nenhuma benfeitoria poderia ser construída naqueles terrenos, porque a usina nada reconheceria do que fosse construído, posterior ao referido cadastramento. Além disso, a escola daquela comunidade foi desativada, deixando as crianças sem possibilidade de estudo.

Desta forma, pelo espaço de dois anos, as pessoas ficaram sem trabalho, comprando o que lhes era necessário na cidade e, voltando a desenvolver o seu roçado porque esta era a única alternativa para que não padecessem de fome.

Para complicar mais a situação da comunidade ribeirinha apareceram em sua área o Conselho Tutelar e a Assistência Social que passaram a pressionar a população porque as crianças não mais estavam estudando, pelas razões anteriormente colocadas.

Além das dificuldades já salientadas, a pesca que era uma garantia e uma importante parte da alimentação desta comunidade, tornou-se cada dia menos produtiva, tendo em vista as ações de engenharia desenvolvidas naquela área, por conta da usina em construção.

Assim, entre 2011 e 2014, os cadastros realizados pela usina foram várias vezes refeitos, obrigando as famílias a esperar por uma definição sobre qual tratamento receberiam.

Enfim, foi a partir do instrumento cadastral que a usina definiu quem seria ou não atingido pelo empreendimento, isto é, quem deveria ser alvo de reparação pelos danos sofridos, quem seria deslocado e quem não seria merecedor de qualquer indenização.

Observamos, no decurso deste tempo, uma ausência de diálogo entre a usina e as pessoas prejudicadas pela construção da referida. Entrementes, teremos que considerar que várias pessoas não entraram no cadastro por não estarem presentes no seu local de moradia, quando os representantes do empreendimento por lá passaram para resgatar as suas situações.

Além disso, os aludidos representantes consideraram vários núcleos familiares como pertencentes a uma única família. Ainda, outras pessoas, não tiveram suas roças avaliadas e contabilizadas para posterior indenização, porquanto, na visão da empresa, elas não foram consideradas produtivas. Dessa maneira, pomares e açaizais foram considerados nativos e em consequência, não entraram no mérito de compensações.

Tendo em vista essa dura realidade, o Ministério Público Federal foi procurado pelos ribeirinhos, convocando, em junho de 2015, uma Inspeção Interinstitucional para verificar em campo, o processo de deslocamento dos ribeirinhos. A ação resultou em um relatório com 55 constatações que indicaram ameaças aos direitos humanos e a inviabilidade do modo de vida dos ribeirinhos. 
Em resposta, o Ibama, que licenciou a obra, suspendeu as remoções, incluindo na licença de operação da usina, a obrigação do empreendedor em garantir o reassentamento dos ribeirinhos nas margens do Rio Xingu.

Todavia, a empresa arvorou-se em decidir quem era ribeirinho ou não e consequentemente, quem teria ou não direito ao ressarcimento financeiro, baseando-se em cadastros que não tinham sido realizados com o propósito de distinguir a finalidade supracitada.

Para culminar, os critérios para a identificação das moradias não se basearam nas declarações dos moradores, mas mediante a avaliação dos funcionários da empresa.

Como resultado desta avaliação, a empresa não atentou para o fato de que os ribeirinhos viviam em um sistema de dupla moradia, isto é, tinham uma casa na cidade e outra às margens do rio. A residência na área urbana representava a sua garantia para a obtenção de serviços e comércio existentes na cidade e a moradia próxima ao rio era o lugar onde realizavam as suas atividades produtivas ligadas à lavoura, à pesca e ao extrativismo. Portanto, é lamentável constatarmos que no momento em que os ribeirinhos foram cadastrados tiveram que optar por uma ou outra residência.

Com esse tipo de encaminhamento, a usina acarretou a completa dispersão da comunidade familiar. Assim sendo, aconteceu que um só membro da família foi reconhecido como ribeirinho, detendo o direito de retornar à beira do rio. Os demais familiares ficaram dispersos na cidade de Altamira.

Anteriormente, toda a família morava junto, mas após essa decisão da usina, os familiares ficaram separados. Essa situação chocou-se com o projeto de vida dos ribeirinhos que reconhecidamente desejavam que todos os seus familiares permanecessem juntos, porque a casa, a roça, a rede de relações, o rio e a rua eram elementos estruturantes da sua própria vida.

Portanto, tendo em vista um cadastramento questionável, os ribeirinhos tiveram toda a sua organização social duramente atingida.

Finalmente, em função do cadastramento elaborado pela usina, ficou a partir dele especificado quem seria indenizado em dinheiro, quem teria direito ao reassentamento, na cidade, na zona rural ou na beira do rio e quem teria apoio para a pesca. Observamos que a usina, adotando este comportamento, chegou ao ponto de pretender definir a identidade das pessoas integrantes da comunidade ribeirinha.

Como resultado, muitas famílias venderam a carta de crédito entregue pela usina, como indenização, usando o dinheiro para garantir uma residência na cidade. Na sequência dos acontecimentos, vários ribeirinhos perderam as suas casas na cidade, tendo ocorrido mais uma dispersão das famílias para outros bairros periféricos da cidade de Altamira, onde atualmente, são encontrados os Reassentamentos Urbanos Coletivos, construídos pela usina. 
De toda essa situação, concluímos que sem o rio e sem a roça, os ribeirinhos acabaram procurando outros serviços.

Chegamos, portanto, a conclusão que de acordo com o Plano Básico Ambiental deveriam ter sido ofertadas aos moradores atingidos opções equivalentes ao que tinham antes do deslocamento forçado. Entretanto, infelizmente, não foi o que constatamos.

Em um território radicalmente transformado para dar lugar à hidrelétrica de Belo Monte, os ribeirinhos lutam para serem ouvidos e tratados com dignidade. 0 retorno para a beira do rio é a condição fundamental para que essa população possa manter seu modo de vida.

Em novembro de 2016, cerca de oitocentas pessoas, a maioria ribeirinha, deslocaram-se até a cidade de Altamira, para finalmente, serem ouvidas em uma audiência que durou doze horas. Na reunião, os ribeirinhos fizeram-se ouvir, denunciando as violações aos seus direitos e exigiram das autoridades presentes, Ibama, Usina e Ministério Público Federal, o respeito às condicionantes já há muito violadas.

Resultado de um longo processo de articulação, os ribeirinhos criaram o chamado Conselho Ribeirinho, que se configurou como uma instância soberana para estabelecer o diálogo com a usina. Este Conselho tem como prerrogativa trabalhar no reordenamento territorial da região.

Assim, a luta se fortaleceu e o retorno para a beira do rio não se configurou mais como uma demanda individual, porém, uma exigência coletiva de uma população tradicional do Rio Xingu.

O grupo de conselheiros é formado por representantes das localidades do Costa Júnior, Bacabal, Bom Jardim, Meranda, Poção, Barriguda, Babaquara, Arapujá, Paratizão, Paratizinho, Palhal, Cotovelo, Trindade e Arroz Cru, todas atingidas pela formação do reservatório da usina.

Por conhecerem o território e seus usos, os ribeirinhos são por meio do Conselho, os únicos em condições de indicar quem são os ribeirinhos e qual é a correta atribuição de áreas para o reassentamento, tendo em vista a reconstrução do território desfeito pela construção da usina. É o Conselho, e não mais a usina que vai determinar quem é ou não é ribeirinho (FRANCESCO; HARARI, 2017).

\section{O AUTOGOVERNO ZAPATISTA}

A partir da "Escuelita", os integrantes de Chiapas visaram educar-se pelo contato com centenas de camponeses maias que praticavam cotidianamente, o autogoverno.

$\mathrm{Na}$ inauguração da "Escuelita", em 2013, foi evocado o essencial: a experiência zapatista rompeu há 23 anos com os princípios seculares que, atualmente estão em crise no que concerne à representação política, à delegação do poder e à separação entre governantes e governados que estão presentes na fundação do Estado e na democracia moderna. 
Estimamos que nessa região de florestas e montanhas que cobrem um terço da superfície do estado de Chiapas (28 mil quilômetros quadrados, quase o tamanho da Bélgica), de 100 mil a 250 mil pessoas segundo estimativas formam a base de apoio do zapatismo, isto é, aqueles que o reivindicam e dele participam.

A experiência zapatista é uma importante experiência de autogoverno coletivo da história moderna. Assim, o zapatismo manteve-se firme até hoje. 0 movimento rompeu com o Estado, solidificou suas bases e delineou uma autonomia política inédita, levada à termo, hoje, pela primeira geração nascida após a revolta de 1994, mediante o abandono progressivo e pragmático da crença no Estado e no vanguardismo leninista no início do processo.

O desafio dessa proposta foi a mudança da natureza do poder político e, na falta de poder, leválo a uma escala maior. Assim sendo, as crianças de 1994, são atualmente, os quadros do zapatismo, sem cooptação ou traição, demonstrando a vida cotidiana das comunidades zapatistas, no presente.

Na visão do zapatismo, o capitalismo não vai parar, significando portanto, que os membros deste movimento estão se preparando para desenvolver uma série de realidades sem o mesmo, o que mostra o Conselho de Bom Governo (Junta de Buen Gobierno) de Morelia, a menos povoada das cinco zonas zapatistas.

Situado no coração da zona, a 1.200 metros de altitude, o caracol de Morelia está localizado em uma colina de exuberante vegetação. 0 termo caracol se refere à lentidão necessária da política e também, a alguns edifícios de reunião que são os escritórios do chefe local de cada zona. 0 caracol é um mirante de pastos e cultivos: 700 hectares de terras recuperadas, para 7 mil habitantes espalhados sobre um território amplo.

Entre a quadra de basquete e o auditório de tijolos pintados, algumas dezenas de homens e mulheres deixam o caracol com mochilas nas costas, após três dias de reuniões, mostrando-se preocupados com os debates sobre as tarefas assumidas por cada um, voluntariamente, desde a divisão das colheitas até a construção das escolas.

As pessoas não têm a intenção de espalhar o zapatismo, que é muito particular e sim a ideia que subjaz à experiência: a autonomia geral. Portanto, há um coletivo por setor de produção, da rádio ao artesanato têxtil, passando pela apicultura. Com 140 cabeças de gado e 10 hectares de plantações de milho (milpas), a zona conquistou a autossuficiência alimentar graças aos seus pomares, granjas, 5 hectares de café e suas padarias cooperativas.

Os excedentes são vendidos aos não zapatistas da região, os "partidistas", que vivem de subsídios do Partido Revolucionário Institucional (PRI), que está atualmente no poder e subsidia alguns vilarejos em troca de trabalho. 
Indiretamente, são os fundos do governo que permitem aos zapatistas comprar, em regime de propriedade coletiva, o que eles não produzem: máquinas, material de escritório e os poucos veículos que levam as pessoas às reuniões e aos quatro cantos da zona.

Os projetos individuais, como a montagem de uma cantina-mercearia, são financiados pelos bancos autônomos zapatistas (Banpaz ou Banamaz), que fazem empréstimos à taxa de $2 \%$. Em toda a zona, as pessoas se alimentam de forma frugal e tradicional, sem a ajuda do Estado ou de ONGs: arroz, tortillas, frijoles (feijão preto), café, algumas frutas e mais raramente, frango, ovos e cana de açúcar.

Registramos poucos computadores e livros nas residências, bem como poucos carros e roupas sóbrias: as condições materiais são mínimas, não faltando nada de essencial.

Os encarregados voluntários do caracol de Morelia assinalam as três missões sociais assumidas pela coletividade: educação, saúde e justiça, desempenhadas em regime de turnos, por "promotores" benfeitores, em lugar de professores, médicos e juízes. Enquanto estão em missão, os seus vizinhos se ocupam de suas terras.

Por outro lado, se as seiscentas escolas zapatistas, das cinco zonas, propuserem três ciclos de estudos, o restante será discutido coletivamente, adequando-se às necessidades locais, sejam elas relacionadas ao ritmo de cada um ou aos programas e calendários escolares.

Todavia, existem em toda parte, cursos de espanhol e línguas indígenas, história colonial e educação política (crítica ao capitalismo, estudo de lutas sociais em outros países), matemática e ciências naturais ("a vida em meio ambiente").

A partir do segundo ciclo, com 15 anos, os jovens, todos alfabetizados podem propor desempenhar uma tarefa, após votação em assembleia e uma formação de três meses. Somada aos processos, na saída de San Cristóbal, a única universidade zapatista, fundada por Raymundo Sánchez Barraza, abrange o Centro Indígena de Capacitação Integral (Cideci). Neste Centro, tudo que existe é resultante do trabalho dos estudantes. Cerca de duzentos jovens aprendem, anualmente, a fabricar sapatos, teologia ou a utilização de máquinas de escrever, mais seguras que os softwares de edição de texto, devido aos cortes frequentes de eletricidade, assim como um seminário político às quintasfeiras.

Inspirados nos primeiros profetas indígenas, o Centro Indígena de Capacitação Integral (Cideci), acolhe também, os grandes Colóquios Zapatistas. 0 último, em dezembro de 2016 foi sobre as Ciências Exatas "contra ou a favor" da autonomia (ConCiências).

Além disso, o sistema de saúde é confiável, a partir de casas de saúde que asseguram cuidados básicos de qualidade, de ecografia a exames oftalmológicos. Cada caracol conta com uma clínica, na qual cirurgiões externos voluntários realizam as cirurgias e as ONGs fornecem os medicamentos alopáticos. 0 uso de ervas medicinais e terapias tradicionais são incentivados por toda a parte, enfatizando-se a prevenção. 
A justiça zapatista, assegurada por voluntários e comissões ad hoc, tratam de casos em geral leves, desacordos sobre as terras ou os raros conflitos internos entre os vilarejos, visando antes reparar do que punir, isto é, o diálogo com o acusado e trabalhos coletivos, em lugar de detenção (existe apenas uma prisão para o conjunto das cinco zonas), sem fiança ou mecanismos de corrupção.

A proibição do álcool, que as mulheres impuseram no âmbito de sua "lei seca" é a primeira das leis zapatistas que foram colocadas em votação e que muito contribuiu para a diminuição da delinquência.

Atualmente, há a prática crescente de trazer os "partidistas" para trabalharem nos serviços públicos zapatistas, sendo permitida a sua contratação e, assim, modificar a relação clientelista permeada pela burocracia e pela dependência e esmolas do partido.

Deste modo, a dependência tem sido o que os zapatistas, passo a passo, buscaram eliminar, até mesmo a relacionada às ONGs. Entretanto, a autonomia, "processo sem fim", segundo eles, continua parcial e muitas vezes "remendada". Ressaltamos que a eletricidade procede dos mesmos cabos da operadora nacional, ainda que sem custos e, alguns produtos dependem de compras coletivas, como o óleo de cozinha e os telefones celulares.

Essa experiência singular assume suas tentativas e arbitragens delicadas, sendo o seu princípio de aprendizagem, caminhar perguntando. Já a expressão mandar obedecendo, afixada por toda a parte, sugere que diante do horizontalismo puro dos fantasmas anarquistas, convém sempre mesclar uma dose mesmo que marginal de organização e eficácia vertical.

As comunidades são consultadas por meio dos conselhos da zona, mais por iniciativa destes últimos, que formulam e submetem as suas propostas e se necessário, organizam as votações.

As tarefas voluntárias são rotativas e revogáveis, funcionando dentro de uma política não profissionalizada, sendo os mais competentes que as ocupam, porque são mais eleitos do que os outros.

Reconhecemos que a partir de consultas minuciosas, nem sempre o povo está atento à uma concepção processual e evolutiva, na qual se inventa e testa constantemente, seja em relação às regras de voto ou à duração e aos critérios das tarefas.

Na gênese do autogoverno acima discutido está o Exército Zapatista de Libertação Nacional (EZLN), que surgiu na floresta, em uma manhã de janeiro de 1994. Essa estrutura militar vertical foi dotada de uma instância de comando, o chamado Comitê Clandestino Revolucionário Indígena (CCRI).

O Exército Zapatista (EZLN) sempre zelou pela perenidade da experiência, decidindo, todavia, que deveria se retirar do funcionamento político em 2003, quando ocorreu a ruptura com o Estado mexicano e quando do advento da instauração do sistema de autogoverno.

O autogoverno passou a funcionar, então, em três níveis após a reordenação territorial, a qual refez as anteriores divisões administrativas: o da comunidade de cada vila, onde atuam agentes e 
comissões (para a segurança e a produção), o das comunas, que agrupam as vilas (municípios) e, acima dos outros, o das cinco grandes zonas, cujos centros são os cinco caracoles (Morelia, La Garrucha, Roberto Barrios, Oventic e La Realidad).

A originalidade do zapatismo é, também, a própria limitação da possibilidade de outros movimentos sociais do mundo replicarem suas invenções e mecanismos: a convergência histórica, em seu seio, de ingredientes heterogêneos e até incompatíveis, que aqui se tornaram indissociáveis. Antes de mais nada, existe o núcleo indígena, que remete aos povos mesoamericanos dessa região (em particular os tzotzils, tzeltales, tojolabales e os choles) e sua tradição cosmoecológica ancestral, mas também, há uma longa história de resistência anticolonial.

Se o indigenismo zapatista mantém aberto o seu potencial de universalização é porque ele se dá menos na chave étnica e mais na memória de cinco séculos de lutas contra a "sangria do Novo Mundo", compreendendo o colonialismo interno das novas elites mestiças do México independente, que pleitearam o direito de representação dos indígenas, confiscando as suas terras e os seus modos de vida.

Não podemos descartar o decisivo papel da Igreja, com particular ênfase ao catolicismo sincrético típico do México, bem como da versão local da Teologia da Libertação, a "Igreja dos pobres", inaugurada no Peru nos anos 1960, a qual se remete à memória colonial mexicana, que desde o século XVI evidenciou que os únicos defensores dos indígenas contra os conquistadores foram os religiosos, como Bartolomé de las Casas e o bispo Vasco de Quiroga, com o seu projeto de uma "República dos Índios".

Convém observar que, sem dúvida, há um elemento marxista-leninista procedente das guerrilhas dos anos de 1960-1970, o qual logrou maior amadurecimento após 1994, na luta antissistêmica e aberta contra o neoliberalismo, a pilhagem dos recursos naturais e a mercantilização de todas as formas de vida que pratica.

Devemos salientar, igualmente, alguns elementos menos óbvios, de tipo libertário e antipatriarcal, como o princípio zapatista da igualdade radical de gênero, o qual se remete a uma filiação pré-colonial.

Devemos destacar, por outro lado, os intercâmbios com uma vasta rede internacional de apoio, convidada a comparecer aos encontros anuais: dezenas de músicos e grupos de rap e ska, com refrões zapatistas (de Rage Against the Machine a Manu Chao, passando por Nana Pancha, do México e, por Pepe Hasegawa, do Japão), milhares de ativistas e intelectuais que participaram dessa construção, como os escritores José Saramago, Gabriel García Márquez, John Berger e Umberto Eco e os acadêmicos Alain Touraine e Noam Chomsky, além de outros famosos, como o ecologista José Bové, o cineasta Oliver Stone ou ainda Danielle Mitterrand. Portanto, são inúmeros os simpatizantes do zapatismo. 
Devemos ponderar a existência de um outro elemento significativo que é a história nacional mexicana, com o seu orgulho e singularidades. 0 projeto zapatista não é de secessão, de independência contra o nacional. A cada reunião do Congresso Nacional Indígena (CNI), criado em 1996, o hino nacional ressoa antes dos cantos zapatistas e o estandarte tricolor do país se move ao vento ao lado da bandeira preta e vermelha. Portanto, segundo os zapatistas, estes não pretendem formar um Estado dentro de um Estado, e sim, um lugar onde poderão ser livres.

Lembremos ainda, que este patriotismo combativo é herança política de dois séculos de lutas, desde a independência em 1810, sendo também a herança homônima do chefe agrário Emiliano Zapata, General do Exército Libertador do Sul, que antes de ser sufocado em 1919, se opôs à tradição latifundiária com o "Plano de Ayala" para a redistribuição das terras e a democracia local.

Não podemos esquecer a superpolitização de um país com uma rede associativa e militante de rara densidade, onde o combate pelo estatuto comunal da terra (o ejido) perdura há mais de um século. No México, misturam-se, simultaneamente aos corporativismos oficiais (principalmente do partido-Estado, o PRI), a mobilização permanente e retórica da justiça social e as diversas insurgências autênticas, cuja repressão sangrenta até o momento, permanece na memória coletiva.

Finalmente, concluímos que o zapatismo é uma combinação da igualdade e da diferença de uma herança comunista de base, bem como da promoção da diversidade étnica e cultural (CUSSET, 2017).

\section{CONSIDERAÇÕES FINAIS}

Através da análise levada à termo referente aos ribeirinhos do Rio Xingu percebemos que os mesmos foram deslocados dos seus lugares de origem e realocados em áreas distantes da beira do rio ou em Altamira ou em zonas rurais.

Os representantes da usina quando realizaram o cadastro dos integrantes da comunidade não levaram em conta que os referidos tinham duas residências, isto é, uma na cidade, a partir da qual efetuavam suas compras rotineiras, das quais constavam produtos essenciais à sua sobrevivência e, por outro lado, suas moradias à beira do Xingu era o lócus das suas atividades produtivas que constavam de roçados, da pesca e de atividades extrativistas. Muitas vezes, tais atividades relativas às áreas onde efetivamente residiam não foram, pelos representantes da usina, devidamente considerados quando entrou no mérito a questão indenizatória. Também, as residências dos ribeirinhos feitas com madeira, barro e palha foram, em ampla escala, diminuídas, quanto ao seu valor indenizatório.

Outras situações extremamente atentatórias aos direitos humanos dos ribeirinhos não foram levadas em conta, como seria justo e desejável, pela Usina. A situação só veio a contemplar os 
ribeirinhos com maior alento e alegria quando foi criado o Conselho Ribeirinho, cujo objetivo foi estabelecer um diálogo mais profundo com os representantes da usina, tendo como questão de maior relevo, o reordenamento territorial das terras que lhes concerniam, com o seu retorno às áreas ribeirinhas, das quais foram anteriormente retirados para ceder lugar ao reservatório principal de Belo Monte.

No que diz respeito ao autogoverno estabelecido no território zapatista, percebemos um continuado diálogo e troca de ideias entre os integrantes da comunidade, principalmente, no que tange à divisão de tarefas rotineiras.

Vimos, igualmente, a singularidade do movimento zapatista através do rearranjo territorial que foi realizado pelos seus protagonistas, visando os interesses maiores de uma comunidade que se destaca pela sua independência, autonomia e grande apelo à democracia coletiva.

\section{REFERÊNCIAS}

CUSSET, F. Quase 15 anos de Autogoverno Zapatista. Em: Chiapas a Revolução continua. Disponível em: http://diplomatique.org.br/em-chiapas-arevolucao-continua/. Acesso em: 14 de junho de 2017.

FERNANDES, Bernardo Mançano. A Ocupação como Forma de Acesso à Terra. In: XXIII, Congresso Internacional da Associação de Estudos Latino-Americanos, 2001. Washington - DC, 2001.

FRANCESCO, A.; HARARI, I. A Luta dos Ribeirinhos do Rio Xingu. Será que todo mundo evaporou? Disponível em: http://diplomatique.org.br/sera-que-todomundo-evaporou/. Acesso em: 14 de junho de 2017.

SANTOS, M. A Natureza do Espaço. São Paulo: Edusp, 2008.

\section{BIBLIOGRAFIA RELATIVA AO AUTOGOVERNO ZAPATISTA}

COMBES, H. Trajectoires de gauche au Mexique. Paris: Karthala, 2011.

DUTERME, B. Zapatisme: la rébellion qui dure. Alternatives Sud. Vol. 21, № 2. Paris: Centre Tricontinental/Syllepse. Louvain-la-Neuve, 2017.

Enlace Zapatista. Disponível em: http://enlacezapatista.ezln.org.mx>. Acesso em: 29 de outubro 2016.

GALEANO, E. Les Veines ouvertes de l'Amerique Latine. Paris: Plon, 1971.

GOUTTE, G. Tout pour tous! L'expérience zapatiste, une alternative concrète au capitalisme. Paris: Libertalia, 2014.

LE BOT, Y. Le Rêve Zapatiste. Paris: Seuil, 1997. 